\title{
A rare manifestation of a common disease: Very early severe preeclampsia in a low-risk patient
}

\author{
Keren Rotshenker-Olshinka ${ }^{1}$, Samueloff Arnon ${ }^{1}$, Ezra Gabbay ${ }^{2}$ and Hen Y. Sela ${ }^{1}$ \\ ${ }^{1}$ Department of Obstetrics and Gynecology, Shaare Zedek Medical Centre, affiliated with the Hebrew University, Jerusalem, Israel \\ ${ }^{2}$ Department of Adult Nephrology, Shaare Zedek Medical Centre, affiliated with the Hebrew University, Jerusalem, Israel
}

\begin{abstract}
Background: Classical definition of preeclampsia is based on new onset hypertension and proteinuria presenting after 20 weeks gestation. Early preeclampsia is rare and carries considerable maternal and fetal risks.

Case: A healthy 40-year-old multipara presented at 17 weeks gestation with new onset hypertension and proteinuria. Workup revealed no underlying condition thus diagnosis of severe preeclampsia was established. Termination of pregnancy was performed followed by rapid maternal improvement, supporting our diagnosis.

Conclusion: This is the first report of severe preeclampsia prior to 20 weeks gestation in a patient without risk factors other than age. Earlier severe preeclampsia, though rare, should be considered in the differential diagnosis of new onset hypertension and proteinuria. Reports of such cases increase clinicians' awareness to the atypical presentation of this disorder.
\end{abstract}

\section{Introduction}

The classical definition of preeclampsia is based on new onset hypertension and proteinuria past 20 weeks gestation [1]. Preeclampsia occurring before 24 weeks is almost always associated with fetal demise and carries considerable maternal risks. Termination of pregnancy is therefore generally recommended in such cases [2-4].

We report a case of severe preeclampsia at 17 weeks gestation in a patient without risk factors for preeclampsia other than her age.

\section{Case}

A 40-year-old grand multiparous woman presented to our institution at 17 weeks gestation with severely elevated Blood pressure (BP) and new onset proteinuria. Her past medical history was unremarkable. The present pregnancy was her fifteenth and was uncomplicated until admission. Previous pregnancies, all with the same partner, included four early non-consecutive miscarriages and ten uneventful pregnancies without hypertensive disorders of pregnancy, small for gestational age infants, placental abruption or evidence of placental insufficiency.

She had no symptoms of preeclampsia upon admission other than elevated BP; her physical examination, including fundoscopy, was normal. Initial workup included a complete blood count which showed mild anemia with no signs of hemolysis (Hemoglobin $10.6 \mathrm{~g} / \mathrm{dL}$ ), a normal platelet count, mildly elevated liver transaminases ( AST 48 IU/L, ALT 76 IU/L), and normal creatinine. Twenty-four hour urine collection revealed severe proteinuria with an elevated urinary proteinto-creatinine ratio (UPCR) (Protein/urine $6465 \mathrm{mg} / 24 \mathrm{~h}$, UTPCR 6.93 $\mathrm{mg} / \mathrm{mg}$ ). An echocardiogram was normal.

Fetal ultrasonography examination during hospitalization showed a viable singleton pregnancy, biometry compatible with 16 weeks gestation, a mildly thickened placenta with few cystic findings, and no evidence of placental abruption. Oral Methyldopa therapy was initiated and increased to the maximal daily dose. Oral Labetalol therapy was later added. Intravenous Hydralazine therapy was required on several separate occasions. Differential diagnosis included early severe preeclampsia or an underlying glomerular disease. Further workup included laboratory testing: urine analysis and biochemistry, blood coagulation, biochemistry and protein electrophoresis, and detailed immunology and serology testing, that were all normal except cryolubulin testing that was initially positive, but showed only traces on repeated measurement. Renal ultrasound including Doppler of the renal veins was normal as well. These findings did not support a primary or secondary glomerular disease or a paraproteinemia as the cause of proteinuria in this patient. Amniocentesis revealed normal fetal karyotype.

Ten days after initial presentation, BP continued refractory to multidrug therapy and remained consistently elevated, at times to the severe range. Repeat laboratory testing revealed no evidence of HELLP syndrome. Renal biopsy was considered. However, given the lack of evidence for a renal disease and potential risks of a renal biopsy during pregnancy, the procedure was not performed.

In the absence of evidence of other etiology, the diagnosis of early severe preeclampsia was made, even though an extremely rare phenomenon before 20 weeks gestation. Termination of pregnancy was recommended and performed by Misoprostol and curettage.

Correspondence to: Keren Rotshenker-Olshinka MD, Department of Obstetrics and Gynecology, Shaare Zedek Medical Center, Jerusalem, Israel, Tel: +972508685912; E-mail: Kerenlogic@hotmail.com

Received: September 18, 2016; Accepted: October 18, 2016; Published: October 24, 2016 
Table 1. Cases reported.

\begin{tabular}{|c|c|c|c|c|c|}
\hline Study (year) & $\begin{array}{l}\text { GA at } \\
\text { presentation }\end{array}$ & Parity & Risk factors & $\begin{array}{l}\text { Obstetric } \\
\text { outcome }\end{array}$ & Maternal outcome \\
\hline Brittain et al. (1995) & 18 & & Partial molar pregnancy & TOP & \\
\hline \multirow{3}{*}{$\begin{array}{l}\text { Asulyman et al. } \\
\text { (1996) }\end{array}$} & 17 & 1 & APLA & MA at 18 weeks & \\
\hline & 19 & 2 & APLA, Previous preeclampsia & $\begin{array}{l}\text { IUFD at } 20 \\
\text { weeks }\end{array}$ & Normotensive 1 year post evacuation \\
\hline & 17 & 2 & APLA & MA at 18 weeks & Normotensive 8 months post evacuation \\
\hline $\begin{array}{l}\text { Nugent et al. } \\
(1996)\end{array}$ & 19 & 1 & $\begin{array}{l}\text { Twin pregnancy, Triploidy } 69, \mathrm{XXY} \text { of one } \\
\text { twin }\end{array}$ & \begin{tabular}{l|} 
TOP via \\
Hysterotomy
\end{tabular} & Normotensive 4 days post termination \\
\hline \multirow[t]{2}{*}{$\begin{array}{l}\text { Rahimpanah et al. } \\
(2000)\end{array}$} & 17 & 1 & $\begin{array}{l}\text { New partner in index pregnancy, Triploidy } \\
69, \mathrm{XXY}\end{array}$ & TOP at 17 weeks & Normotensive post termination \\
\hline & 17 & 3 & Triploidy $69, \mathrm{XXY}$ & TOP & \\
\hline Craig et al. 2000 & 17 & 0 & Triploidy $69, \mathrm{XXY}$ & TOP & \\
\hline $\begin{array}{l}\text { Hazara et al. } \\
(2003)\end{array}$ & 18 & 2 & $\begin{array}{l}\text { AMA, Previous preeclampsia, new partner in } \\
\text { index pregnancy }\end{array}$ & TOP at 19 weeks & Complete remission post termination \\
\hline $\begin{array}{l}\text { Imasawa et al. } \\
\text { (2006) }\end{array}$ & 15 & 0 & AMA, Twin pregnancy & TOP at 18 weeks & $\begin{array}{l}\text { Normotensive and resolution of proteinuria at } 3 \text { weeks and } 3 \text { months post } \\
\text { termination, respectively }\end{array}$ \\
\hline $\begin{array}{l}\text { Thomas et al. } \\
\text { (2012) }\end{array}$ & 16 & 3 & $\begin{array}{l}\text { AMA, CHTN, Previous preeclampsia and } \\
\text { gestational HTN }\end{array}$ & TOP at 23 weeks & Normotensive 14 weeks post-termination \\
\hline
\end{tabular}

A normal appearing male fetus was delivered. Pathology examination or genetic testing was refused on religious grounds. Pathology examination of the placenta revealed severe degenerative changes in chorionic villi and fibrinoid necrosis in the decidua. Maternal condition improved significantly and rapidly. On postoperative day five she was discharged home with oral antihypertensive therapy: Ramipril 5mg and Bisoprolol $2.5 \mathrm{mg}$ once daily. Urinary protein excretion as assessed by UPCR was $0.482 \mathrm{mg} / \mathrm{mg}, 0.075 \mathrm{mg} /$ $\mathrm{mg}$ and $0.091 \mathrm{mg} / \mathrm{mg}$ at 7,37 , and 60 days post discharge, respectively (correlating to approximately 480, 75 and $91 \mathrm{mg}$ of 24 hour urinary protein excretion, respectively). BP normalized rapidly and all antihypertensive therapy was discontinued by post discharge day 10 . During 3 months of follow up all BP measurements were normal.

\section{Comment}

New onset hypertension with proteinuria prior to 20 weeks gestation pose a diagnostic and therapeutic challenge, as the traditional definition of preeclampsia, recently revised, includes new onset hypertension and proteinuria or defined systemic signs, first manifesting after 20 weeks gestation [1]. Early severe preeclampsia is a rare condition associated with adverse maternal and fetal outcomes. It is almost always associated with fetal demise and carries considerable maternal risks such as eclampsia, hepatocellular injury, placental abruption, pulmonary edema, renal failure, coagulopathy, cerebrovascular accident, and even death. In one of the largest studies assessing the benefits and risks of expectant management of early severe preeclampsia at less than 26 weeks, $43 \%$ of participants $(22 / 53)$ had at least one major maternal complication. There were no perinatal survivors in those diagnosed at less than 24 weeks (0/12 women) [2]. Termination of pregnancy is therefore generally recommended in cases suspected of very early severe preeclampsia [2-4]. As these cases are extremely rare, the diagnosis may be facilitated by the presence of risk factors such as chronic hypertension, multifetal pregnancy, prior pregnancy complicated by preeclampsia, or a new partner [5-6]. To date, very few cases have been reported in the medical literature on early severe preeclampsia prior to 20 weeks gestation. Out of the eleven cases reported (Table 1), only three were isolated and eight were associated with either partial mole, triploidy, or antiphospholipid antibody syndrome. Furthermore, even the three "pure" cases had risk factors for preeclampsia; all women were of advanced maternal age, one had a twin pregnancy, the second had history of prior preeclampsia and a new partner in the index pregnancy, and the third had a history of chronic hypertension and prior pregnancies complicated by early onset preeclampsia [7-9]. The current case is unique as we diagnosed severe preeclampsia at less than 20 weeks in a healthy multiparous woman without medical risk factors for preeclampsia, aside from her age. The patient underwent extensive workup that did not reveal any other causes for her condition. The rapid clinical improvement in both $\mathrm{BP}$ and proteinuria following termination of pregnancy further supports the diagnosis of preeclampsia.

In conclusion, severe preeclampsia at less than 20 weeks, though extremely rare, should always be considered in the differential diagnosis of new onset hypertension and proteinuria in early pregnancy. Reports of such cases should increase clinicians' awareness of the atypical presentation of this dangerous disorder.

\section{References}

1. Report of the American College of Obstetricians and Gynecologists' Task Force on Hypertension in Pregnancy (2013) Hypertension in pregnancy. Obstet Gynecol 122: 1122-1131. [Crossref]

2. Belghiti J, Kayem G, Tsatsaris V, Goffinet F, Sibai BM, et al. (2011) Benefits and risks of expectant management of severe preeclampsia at less than 26 weeks gestation: the impact of gestational age and severe fetal growth restriction. Am J Obstet Gynecol 205: 465. [Crossref]

3. Sibai BM, Stella CL. (2009) Diagnosis and management of atypical preeclampsiaeclampsia. Am J Obstet Gynecol. 200: 481. [Crossref]

4. Norwitz ER, Funai EF (2008) Expectant management of severe preeclampsia remote from term: hope for the best, but expect the worst. American journal of obstetrics and gynecology 199: 209-212.

5. Duckitt K, Harrington D (2005) Risk factors for pre-eclampsia at antenatal booking: systematic review of controlled studies. Bmj 330: 565. [Crossref]

6. Deen ME, Ruurda LG, Wang J, Dekker GA (2006) Risk factors for preeclampsia in multiparous women: primipaternity versus the birth interval hypothesis. J Matern Fetal Neonatal Med 19: 79-84. [Crossref]

7. Imasawa T, Nishiwaki T, Nishimura M, Shikama N, Matsumura R, Nagai M, et al.

8. (2006) A case of "pure" preeclampsia with nephrotic syndrome before 15 weeks of gestation in a patient whose renal biopsy showed glomerular capillary endotheliosis. American journal of kidney diseases : the official journal of the National Kidney Foundation. 48: 495-501. 
9. F.P. Schena, William Thomas, Meryl Griffiths, Catherine Nelson-Piercy, Kim Sinnamon (2012) Pre-eclampsia before 20-week gestation: diagnosis, investigation

10. and management. Clin Kidney J 5: 597-599. [Crossref]
11. Hazra S, Waugh J, Bosio P. (2003) 'Pure' pre-eclampsia before 20 weeks of gestation: a unique entity. BJOG : An International Journal of Obstetrics and Gynaecology.110: $1034-1035$.

Copyright: (C2016 Rotshenker-Olshinka K. This is an open-access article distributed under the terms of the Creative Commons Attribution License, which permits unrestricted use, distribution, and reproduction in any medium, provided the original author and source are credited. 